\title{
A Transferência como Conceito Fundamental da Praxis Psicanalítica
}

Resumo: A insatisfação dos pacientes com eles próprios, constatada na experiência clínica, foi tomada como uma inquietação a ser trabalhada. $\mathrm{O}$ conceito de satisfação é abordado no intuito de saber de onde ela vem e como ela é trabalhada na praxis psicanalítica. Esta se estabelece por meio da linguagem, possibilitando ao sujeito simbolizar aquilo que se constitui enquanto falta. Isso que permanece inacessível para o sujeito constitui o real. A satisfação busca satisfazer a pulsão, que é uma força constante. Disso advém o princípio de prazer que busca fazer com que a excitação retorne ao mais baixo nível, evitando o desprazer. A revelação do evento traumático causaria desprazer ao sujeito e, por isso, as resistências operam para que o conteúdo inconsciente continue reprimido. É devido a isso que a satisfação da pulsão nunca é completa. Essa busca de satisfação, que sempre encontra um objeto diferente, condena o sujeito à repetição. A atuação por meio da repetição impede o recordar, mantendo o material reprimido. É a partir da transferência que o sujeito pode tomar consciência desses fenômenos. A transferência se dá por meio da linguagem, na medida em que o sujeito é capaz de significar seus atos e seus objetos. Portanto, ela se instaura enquanto conceito fundamental da praxis psicanalítica.

Palavras-chave: satisfação, pulsão, repetição, transferência, interpretação.

\section{Introdução}

O interesse que se estabelece, é a partir de uma escuta que enfatiza a questão da insatisfação dos pacientes com eles próprios. É como se houvesse uma constante busca em alcançar a felicidade e, conseqüentemente, a satisfação de algo que a traga. No entanto, essa satisfação não é completa. Isso ocorre porque há um representante inconsciente recalcado que, através das resistências que impedem que esse conteúdo seja revelado ao consciente, privam o sujeito do desprazer, não fazendo com que ele se depare com o evento traumático recalcado. Portanto, o sujeito busca um novo objeto para se satisfazer que, da mesma forma,

\footnotetext{
${ }^{1}$ Graduada em Psicologia na UFPR e pós-graduanda em Psicologia Clínica - Abordagem Psicanalítica, pela PUC-PR.
} 
o mantém distante de seu conteúdo recalcado. Nessa busca constante, ocorre que o paciente dá satisfação a algo por meio do qual ele acredita obter prazer. E isso que busca ser satisfeito em detrimento do prazer é a pulsão. Essa insistência de satisfazê-la faz com que se tenha sempre um retorno ao mesmo ponto, condenando o sujeito à repetição.

Posteriormente, investigar-se-á a respeito de como esses conceitos operam na praxis psicanalítica, a partir da qual o homem busca compreender-se a si mesmo. Percebe-se que há sempre um retorno do paciente àquilo que ele busca, uma forma de repetição que se perpetua no decorrer de sua vida e que, ao mesmo tempo, torna-se um empecilho na descoberta daquilo que o impulsiona a alcançar a satisfação. Atrelado a esse empecilho, está o evento traumático, o qual é mantido velado, afastando o sujeito do desprazer.

Além dessa repetição que se manifesta nas vivências do sujeito, há uma em especial que se reproduz nas diversas relações do paciente e, sobretudo, entre este e o analista. Esta seria a transferência, fenômeno que se dá por meio da linguagem, no qual o paciente convoca a pessoa do analista à interpretação de seus significantes. Abordando esses quatro conceitos - satisfação, pulsão, repetição e transferência - far-se-á uma articulação no intuito de fundamentar a hipótese de que é através da transferência e da repetição que a satisfação da pulsão é trabalhada na praxis psicanalítica, consistindo, portanto, em seus conceitos fundamentais.

\section{Satisfação, Pulsão, Repetição e Transferência}

A experiência clínica pode trazer algumas inquietações a respeito de conceitos da teoria analítica. A partir da escuta do paciente, observa-se que a queixa trazida ao analista, aquilo que o incomoda, a questão que o levou à análise, muitas vezes diz respeito à insatisfação do paciente com ele próprio. Essa insatisfação leva a crer que o paciente está em busca de sua felicidade pessoal, como um meio de satisfazer a si próprio. A partir da satisfação daquilo que o paciente acredita querer satisfazer, enfim, suas vontades, ele espera alcançar a felicidade. "O que chamamos de felicidade no sentido mais restrito provém da satisfação (de preferência, repentina) de necessidades represadas em alto grau, sendo, por sua natureza, possível apenas como manifestação episódica" (FREUD, 1930 , p.95). Na tentativa de alcançar essa sua felicidade, o paciente segue suas vontades, como uma forma de realizar aquilo com o que ele estaria contentado.

A inquietação que se tem, no entanto, está em saber o que ocorre que faz com que o paciente, mesmo ao ir em busca de suas vontades, continue a sentir-se descontentado, insatisfeito consigo próprio. Naquilo em que ele acredita 
encontrar sua felicidade, por mais que isso seja realizado, ele continua na sua insatisfação. Mas mesmo nessa insatisfação, o paciente permanece agindo da mesma forma, como se estivesse satisfazendo seu contentamento. Ou seja, isso por meio do que o paciente acredita se satisfazer é realizado, mas ele continua a se sentir descontente, como se ainda faltasse algo para alcançar sua felicidade. É como se esta, estivesse atrelada a algo que o paciente espera experimentar e satisfazer. Dessa forma, ele encontra meios e formas de atingir seu objetivo, ou seja, algo ou alguém por meio do qual ele possa se satisfazer, mas permanece nessa busca, pois acredita haver algo a mais para satisfazer. Essa questão pode ser vista na citação de Lacan:

É claro que aqueles com quem temos que tratar, os pacientes, não se satisfazem, como se diz, com o que são. E, no entanto, sabemos que tudo o que eles são, tudo o que eles vivem, mesmo seus sintomas, depende da satisfação. Eles satisfazem algo que vai sem dúvida ao encontro daquilo com o que eles poderiam satisfazerse, ou talvez melhor, eles dão satisfação a alguma coisa. Eles não se contentam com seu estado, mas, estando nesse estado tão pouco contentador, eles se contentam assim mesmo. Toda a questão é justamente saber o que é esse se que está aí contentado. (LACAN, 1964, p.158)

Cabe, portanto, compreender a que se refere o conceito de satisfação. O interesse que surge a partir de então, está em saber o que se quer satisfazer e de que forma essa satisfação é trabalhada, tanto pelo analista como pelo paciente, na praxis psicanalítica. Antes de introduzir o conceito de satisfação, convém ressaltar o termo praxis para uma melhor compreensão do que está sendo articulado enquanto o trabalho que ocorre na análise.

Segundo Japiassú (1996, p.219), o termo praxis está relacionado aos problemas centrais do homem, que busca transformar o mundo a sua volta ao mesmo tempo em que este transforma a si mesmo. Na psicanálise, esse termo estaria atrelado aos problemas práticos da existência concreta do homem, que devem ser solucionados e compreendidos através da praxis psicanalítica. Lacan utiliza esse termo para designar uma "ação realizada pelo homem, qualquer que ela seja, que o põe em condição de tratar o real pelo simbólico" (LACAN, 1964, p.14). Esta definição pode ser compreendida a partir da teoria lacaniana. Nesta, o real é definido como o impossível, que não pode ser simbolizado pelo sujeito, na palavra ou na escrita. Isso quer dizer, que o real é aquilo ao que não se pode dar significantes, que são representações que dão sentido ao ato e ao objeto do sujeito, que, por sua vez, determina-se por meio daqueles. É por essa falta de simbolização que o real se torna impossível, pois uma vez que não há significantes, o sujeito não tem como assimilá-lo. Já o simbólico seria uma 
"função complexa e latente que envolve toda a atividade humana, comportando uma parte consciente e outra inconsciente, ligadas à função da linguagem e, mais especialmente, à do significante" (CHEMAMA, 1995, p. 199). Portanto, o sujeito trata o real por meio da linguagem, na qual se pode distinguir o código da mensagem que é dado pela fala, através da palavra. Então, por meio do simbólico, o sujeito é capaz de assimilar o objeto, dando-lhes significantes, o que determina suas escolhas. Tratar o real pelo simbólico, seria uma forma de tratar aquilo que não pode ser simbolizado através de um significante que é dado na linguagem. Cabe ao sujeito, enquanto ser falante, dar um significante para aquilo que lhe é inacessível. E é com significantes, com a linguagem, que se trabalha na praxis psicanalítica. Por ora, esta explicação do termo praxis é suficiente para introduzir os conceitos a serem trabalhados que, ao final, serão articulados na praxis psicanalítica.

Então, voltando ao conceito que aqui interessa nessa praxis, a satisfação, deve-se averiguar, primeiramente, o que a impulsiona, o que faz com que o paciente tenha sempre algo a satisfazer e o que é esse algo que está lá para ser satisfeito. Bem, o conceito de satisfação relaciona-se a uma espécie de descarga de energia, que tem caráter fundamental para a vida do sujeito, pois é o fator impulsionador, que faz com que o sujeito esteja sempre em busca de algo para satisfazer essa energia, regulando a excitação somática. Isso que se mantém no sujeito como uma constante, essa energia, essa excitação, é a pulsão. Na verdade, a pulsão se refere às diferentes formas de energias provenientes do organismo e, portanto, deve-se entendê-la como pulsões que, no entanto, contêm as mesmas características.

Freud, em seu artigo Os Instintos e suas Vicissitudes (1915), caracterizou a pulsão de acordo com quatro termos: impulso, fonte, objeto e finalidade. $\mathrm{O}$ impulso seria a expressão da energia pulsional ou, conforme Lacan (1964, p.155), o impulso pode ser identificado com uma pura e simples tendência à descarga. A fonte seria a zona erógena da pulsão, que é qualquer lugar do corpo por ela investido. Já o objeto é a coisa em relação à qual ou através da qual a pulsão é capaz de atingir sua finalidade, ou seja, sua satisfação. O objeto, então, é qualquer coisa que permita a satisfação pulsional, que é a finalidade da pulsão. Portanto, é isso que impulsiona, que se mantém para ser satisfeito, a pulsão. É essa força constante, que move o sujeito, que está lá para ser satisfeita. Trata-se de uma necessidade que deve ser eliminada por meio da satisfação.

O que resta saber, é por que então, o paciente não se satisfaz uma vez que essa pulsão, que se faz presente constantemente no interior do organismo, está buscando justamente a satisfação? Enfim, há no interior do organismo, uma energia a ser descarregada, que busca atingir sua finalidade de satisfação. O que 
ocorre, entretanto, é que a pulsão assume um caráter de multiplicidade pelo fato de serem inúmeros os seus objetos. Isso faz com que a tensão ressurja, renasça sempre em busca de um novo objeto que a satisfaça da mesma forma. Sendo assim, a satisfação nunca é completa, pois a tensão retorna a seu ponto de insatisfação. E o que estaria atrelado a esse inacabamento da satisfação da pulsão?

Antes de responder a essa pergunta, cabe ressaltar que a pulsão é representada por uma idéia. No entanto, esse representante ideacional trata-se de um conteúdo inconsciente, recalcado. Freud, em seu artigo intitulado Repressão (1915), desenvolve que numa primeira fase do recalque, a entrada ao consciente do representante psíquico ideacional da pulsão é negada. Assim sendo, a pulsão permanece ligada a esse representante, de forma inconsciente. Numa segunda fase, outros derivados mentais do representante psíquico, como sucessões de pensamentos vindos de outra parte, são também recalcados. Constata-se que o recalque faz com que a pulsão torne-se inoperante, uma vez que impede que a idéia recalcada seja revelada ao consciente.

Portanto, a satisfação da pulsão encontra-se permeada por esse representante recalcado. Isso leva a crer que seja esse o motivo pelo qual a satisfação não é completa. De fato a pulsão vai em busca dessa satisfação e satisfaz-se, até certo ponto, a partir de determinado objeto. No entanto, se essa satisfação fosse completa, traria à tona o representante ideacional recalcado. Para que isso não ocorra, a satisfação é apenas parcial e faz com que o sujeito vá em busca de outros objetos para satisfazer a pulsão de forma a manter o representante ideacional recalcado, assumindo, a satisfação, caráter provisório. Essa defesa que se impõe para que o material inconsciente não seja revelado, deve-se ao fato de seu conteúdo causar desprazer, levando o sujeito a privar-se deste.

O que fica obscuro, é o fato da satisfação da pulsão, que seria uma fonte de prazer a partir da descarga de energia ou diminuição da excitação, causar desprazer. Isto ocorre em detrimento da pulsão, ou seu representante psíquico, ser derivada do trauma, evento inassimilável para o sujeito, que se mantém recalcado.

No Dicionário de Psicanálise (CHEMAMA, 1995, p. 221) tem-se que o trauma, geralmente, se deve a impressões sentidas ou experimentadas na infância e posteriormente esquecidas. Primeiramente ocorre o evento traumático, ou cena traumática, em que se tem um aumento da excitação, que não é elaborado pela criança. Conseqüentemente, tal evento não constitui nenhuma representação, a não ser defensiva, impedindo que o evento seja revelado. Normalmente, o evento traumático está relacionado ao objeto, podendo ser devido à sua perda ou à sua inadequação. Dessa forma, a criança percebe que o objeto não corresponde à sua expectativa de satisfação. Tem-se uma inadequação das respostas do objeto em 
relação às suas necessidades afetivas. Esse objeto representa o objeto primário do sujeito, ou seja, objeto de amor idealizado como aquele que irá satisfazê-lo. Com isso, o sujeito encontra-se frente ao seu sofrimento em relação ao objeto primário faltante, uma vez que o objeto está abaixo das suas expectativas de satisfação.

Como o trauma ocorre na primeira infância, muitas vezes instaurado antes mesmo da aquisição da linguagem, ele não é simbolizado pelo sujeito. Isso quer dizer que o sujeito ainda não é capaz de colocar em palavras, utilizando-se da linguagem, do simbólico. Portanto, o trauma acaba por não se integrar à consciência do sujeito, permanecendo recalcado. No mesmo dicionário citado acima (Ibid., p.185), o recalque é definido como o processo que afasta do consciente aquilo que pode provocar um desprazer ao sujeito, tratando-se de uma defesa contra as incitações pulsionais. $\mathrm{O}$ recalque faz com que o trauma não seja revelado ao consciente.

$\mathrm{O}$ evento traumático, geralmente, relaciona-se às primeiras experiências de prazer vividas na satisfação das necessidades orgânicas da criança. Esta cria teorias a respeito da sexualidade infantil, envolvendo questões relativas à origem do sujeito, tais como sua concepção, a origem de sua sexualidade e a origem da diferença entre os sexos. Então, o trauma é um evento de natureza sexual. No entanto, os eventos são sempre reelaborados pelo sujeito, mas permanecem sempre integrados ao saber inconsciente. Assim, mesmo posteriormente, com a aquisição da linguagem, o sujeito perde o acesso ao objeto, uma vez que o trauma não foi simbolizado. Freud (1914, p.195) coloca que "há um tipo especial de experiência da máxima importância, para a qual lembrança alguma, via de regra, pode ser recuperada. Trata-se de experiências que ocorreram em infância muito remota e não foram compreendidas na ocasião, mas que subseqüentemente foram compreendidas e interpretadas."

A liberação desse trauma causaria desprazer ao sujeito e, por isso, operam as resistências que mantêm o recalque.Resistência é “... tudo aquilo que entrava o acesso do sujeito à sua determinação inconsciente" (CHEMAMA, 1995, p.192). Ela opera como uma defesa, impedindo que o esquecido volte à consciência. Dessa forma, tais mecanismos, de recalque e de resistência, procuram manter a excitação do organismo no nível mais baixo possível, privando o sujeito do desprazer. Freud $(1909$, p.25) coloca que o recalque evita o desprazer, “... revelando-se desse modo um meio de proteção da personalidade psíquica." Esse movimento de excitação perturba a organização da economia pulsional, que se estabelece pela inércia pulsional, por sua homeostase. $\mathrm{O}$ princípio de homeostase é o fator econômico, que busca a redução da tensão, evitando o desprazer ou produzindo prazer e é relacionado por Freud (1920, p.18) à quantidade de excitação presente na mente. Enquanto o aumento da excitação 
está relacionado ao desprazer, sua diminuição, relaciona-se ao prazer. É esta excitação que o princípio de prazer, conceito formulado por Freud em Além do Princípio de Prazer (1920), procura manter tão baixa quanto possível ou mantê-la constante.

Voltando à questão da felicidade que visam não só os pacientes, mas os homens em geral, esta está relacionada ao fator econômico, pois como coloca Freud (1930, p. 94), a felicidade "por um lado, visa a uma ausência de sofrimento e de desprazer; por outro, à experiência de intensos sentimentos de prazer". Para isso $_{2}$ o sujeito resiste para que o recalcado inconsciente não seja liberado, evitando o desprazer. Também em Além do Princípio de Prazer (1920, p.60), Freud desenvolve a idéia de que o caminho para a satisfação completa, que seria a repetição de uma experiência primária de satisfação, encontra-se obstruído pelas resistências que mantêm os recalques. Assim sendo, a diferença entre o prazer da satisfação conseguido e do exigido seria o fator impulsionador, não permitindo parar em nenhuma das posições alcançadas. Isso que se busca satisfazer, como já dito anteriormente, é a pulsão, que tende a ser um modo fixo para cada sujeito, ou seja, tende-se a construir um objeto e um modo de satisfação da necessidade. $\mathrm{Na}$ concepção freudiana (FREUD, 1915, p. 138), a pulsão é o representante psíquico de uma contínua fonte de excitação proveniente do interior do organismo.

Por tratar-se a pulsão de uma força constante, que impulsiona, alterando a homeostase que corresponde ao princípio de prazer, Lacan (1964, p.174) coloca que "... o caminho da pulsão é a única forma de transgressão que se permite ao sujeito em relação ao princípio de prazer." Isso quer dizer que é a pulsão que altera a homeostase do sujeito; é por causa dela que o sujeito, indo em busca da satisfação, tem sua excitação interna do organismo desequilibrada. Mas ao aumentar essa excitação pulsional, a resistência atua para que não haja desprazer. Com isso, a pulsão não atinge sua finalidade, pois é barrada pelas resistências que impedem que o recalcado seja revelado. É justamente a satisfação da pulsão, sua finalidade, que não se articula por completo. Algo resta desarticulado e, conforme a teoria lacaniana, pode-se dizer que o inacabamento das pulsões é a articulação do real. O real "é definido como o impossível, o real é aquilo que não pode ser simbolizado totalmente na palavra ou na escrita e, por conseqüência, não cessa de não se escrever" (CHEMAMA, 1995, p.182). O fato de o real não poder ser simbolizado totalmente, faz com que o sujeito permaneça em uma constante busca disso que está lá para ser satisfeito. E o que faz com que isso insista é o fato de que "a pulsão apreendendo seu objeto, aprende de algum modo que não é justamente por aí que ela se satisfaz. Pois se se distingue, no começo da dialética da pulsão o Not e o Bedürfnis, a necessidade e a exigência pulsional - é 
justamente porque nenhum objeto de nenhum Not, necessidade, pode satisfazer a pulsão" (LACAN, 1964, p.159).

Ainda em relação à parcialidade das pulsões, esse inacabamento, Lacan (1964, p.167) coloca: “A pulsão é precisamente essa montagem pela qual a sexualidade participa da vida psíquica, de uma maneira que se deve conformar com a estrutura de hiância que é a do inconsciente". A hiância constitui uma estrutura de borda, aquilo que faz borda, que contorna o objeto sem atingir o alvo propriamente dito, não completando a satisfação. Lacan acredita que a sexualidade esteja relacionada às pulsões parciais pelo fato dela ocorrer ao sujeito numa idade muito precoce. Além disso, coloca que é devido ao fator econômico, que busca garantir uma certa homeostase das tensões internas, que a sexualidade só se articula em forma de pulsões parciais. Portanto, o irreprimível das pulsões é impulsionado pela sexualidade recalcada, que busca sua descarga, a obtenção de prazer, visando a satisfação da pulsão. O real, ao contrário, "se distingue (...) por sua separação do campo do princípio de prazer, por sua dessexualização, pelo fato de que sua economia, em seguida, admite algo de novo, que é justamente o impossível" (LACAN, 1964, P.159).

No entanto, a satisfação do paciente é sempre simbolizada, o que quer dizer que ela é sempre posta em palavras, falada. Ao simbolizar algo, utilizandose da linguagem, o sujeito dá representações àquilo que lhe falta ou àquilo que foi perdido, criando assim, significantes que se tornarão representantes do sujeito, determinando-o. Portanto, o sujeito é determinado pelos seus próprios significantes. Ao simbolizar a satisfação, o sujeito faz com que o material inconsciente continue recalcado por meio das resistências. Afinal, no momento em que a satisfação se instaura como significante, ela se afasta de seu verdadeiro objeto, pois este faz parte do real, não podendo ser simbolizado ou assimilado pelo sujeito. Essa perda do objeto faz com que o sujeito crie um novo objeto para satisfazer sua pulsão, ele dá satisfação a um novo alvo. Esse retorno em círculo faz com que a satisfação da pulsão retorne sempre ao mesmo lugar, sempre em busca de um objeto que atinja sua finalidade.

Portanto, por mais que a finalidade da pulsão seja a satisfação pulsional, ocorre que a satisfação da pulsão é atingida sem que seu alvo o seja. Lacan coloca esse inacabamento como sendo um círculo que a pulsão descreve ao redor do objeto que não foi atingido, devolvendo-a a seu ponto de origem e preparando-a para reiniciar um novo trajeto, quase idêntico. Então, conclui: "Se a pulsão pode ser satisfeita sem ter atingido aquilo que, em relação a uma totalização biológica da função, seria a satisfação ao seu fim de reprodução, é que ela é pulsão parcial, e que seu alvo não é outra coisa senão esse retorno em círculo." (LACAN, 1964, p.170). Portanto, o objeto da pulsão é o "completamento" do circuito. A sua 
satisfação está em contornar o objeto, sem atingi-lo, pois o objeto produz um encontro cuja falta recobre a outra. Ou seja, forma-se um círculo em que o sujeito está sempre em busca de um objeto para satisfazer a pulsão, pois uma vez que ela se instala, é preciso lhe dar destino. Uma vez que não atinge seu alvo, que não se completa, a satisfação deixa um espaço que faz com que o sujeito continue em busca de sua satisfação.

Essa perda do objeto condena o sujeito à repetição, uma vez que o que se instaura é a insistência de satisfazer a pulsão. No seminário intitulado $O$ saber do psicanalista (1971-1972), Lacan coloca que é dessa insistência que surge a repetição, porque não se encontra o objeto. A repetição faz com que se instaure a insistência dos significantes, que são os significantes da falta. Afinal, esses significantes operam enquanto representantes da perda do objeto. Sempre que o sujeito fracassa na sua busca do objeto, este é por ele simbolizado, passando a se constituir como significante da falta. Portanto, a perda do objeto, sua falta, é a entrada do significante. $\mathrm{O}$ fato de o princípio de prazer, postulado por Freud, ter como objetivo baixar a tensão faz com que essa insistência se torne contrária a ele, pois ela vai justamente ao encontro do fracasso do sujeito, sua perda do objeto, que pode ser entendida como o encontro com o real. "Eis o que é o precisar repetir tal como o vemos surgir para além do princípio de prazer. Ele vacila para além de todos os mecanismos de equilibração, de harmonização e de concordância no plano biológico" (LACAN, 1954, p. 118-119). Constata-se, então, uma relação entre essa insistência, que burla o princípio de prazer, e a compulsão à repetição. Faz-se necessário, nesse momento, definir o conceito de repetição. Este, muitas vezes, aparece atrelado à reprodução, que é algo que está pronto a trazer uma resposta, na tentativa de completar aquilo que falta, através do registro da linguagem, da função do símbolo, da representação do sujeito. No entanto, o mesmo questionamento de Lacan $(1954$, p.85) se instaura no presente: "O que será que é esta insistência do sujeito em reproduzir? Reproduzir o quê? Será em sua conduta? Será em suas fantasias? Será em seu caráter? Será até mesmo em seu eu? Coisas de todo gênero, registros extremamente diferentes, podem servir como material e como elemento para esta reprodução."

A compulsão à repetição é atribuída por Freud (1920, p.33) ao recalcado inconsciente. Segundo Lacan $(1964$, p. 53) seria a resistência do sujeito que se torna, nesse momento, repetição em ato. Através da repetição, o sujeito repete o material recalcado como se fosse uma experiência contemporânea. No entanto, as resistências do sujeito, que se originam no eu, continuam a atuar, fazendo com que o material recalcado não seja revelado. A repetição faz com que o material recalcado retorne continuamente, sem que o sujeito saiba, pois como o recalcado é simbolizado, o sujeito perde o acesso ao objeto e, portanto, ao seu destino de 
satisfação. "Freud descobre que o que não pode ser rememorado retorna de outra forma, por meio da repetição, por aquilo que se repete na vida do sujeito, sem que o perceba". (CHEMAMA, 1995, p.190).

$\mathrm{O}$ conceito de repetição se encontra atrelado às resistências que mantêm o recalque. Dessa forma, "o paciente não recorda coisa alguma do que esqueceu e recalcou, mas expressa-o pela atuação ou atua-o (acts it out). Ele o reproduz não como lembrança, mas como ação; repete-o, sem, naturalmente, saber que o está repetindo" (Freud, 1914, p.196). Portanto, o que ocorre é que o paciente substitui o recordar, submetendo-se à compulsão à repetição. De acordo com Freud, "quanto maior a resistência, mais extensivamente a atuação (acting out) (repetição) substituirá o recordar". (Ibid., p.197). Pois repetindo, as resistências impedem que o recalcado seja revelado, recordado pelo paciente.

Observa-se que o que o sujeito repete, não tem relação ao prazer, pois muitas vezes, o que ele repete é a cena traumática. Na tentativa de reduzir o trauma, dominando-o e integrando-o na organização simbólica do sujeito, a função da repetição é inútil, visto que não é isso o que ocorre. Na repetição, o sujeito não encontra uma forma de integrar o trauma, mesmo porque, ele o repete sem o saber, de forma inconsciente. Portanto, a repetição constitui um automatismo, precisando sempre ser refeita, perpetuando-se. Aí estaria seu caráter retrógrado, retornando sempre ao mesmo lugar, sendo o inverso do avanço. Mas afinal, qual seria a função da repetição? Se sua função de amenizar o trauma seria inútil, por que então, os pacientes continuam a repetir? Bem, isso se responde de acordo com a resistência que o paciente mantém para que o recalcado não seja liberado. Dessa forma, a função que estaria aí atrelada à repetição seria a de evitar o desprazer, poupando o eu, pois é dele que advém a resistência, do material inconsciente recalcado. Cabe ressaltar que a repetição seria, portanto, atribuída ao inconsciente, ao que está recalcado.

E o que dizer da colocação de Lacan (1964, p.62): “A repetição demanda o novo"? Para falar sobre a repetição, Lacan, no livro 11 do Seminário (1964), retoma a relação que Aristóteles estabelece entre tiquê e autômaton da seguinte maneira: "A tiquê (...) nós a traduzimos por encontro do real. O real está para além do autômaton, do retorno, da volta, da insistência dos signos aos quais nos vemos comandados pelo princípio de prazer. O real é o que vige sempre por trás do autômaton..." (LACAN, 1964, p.56). Portanto, como já visto anteriormente, é a evitação do desprazer que faz com que o autômaton (retorno) opere, repetindo algo que se produz como por acaso, de acordo com sua relação com a tiquê (encontro com o real). O que se produz é um encontro faltoso, pois trata do real, algo de inassimilável, assim como ocorre no trauma. Este é concebido por Lacan (1964, p.57) "como devendo ser tamponado pela homeostase subjetivante que 
orienta todo o funcionamento definido pelo princípio de prazer". Assim, é a redução da tensão que deve operar, fazendo com que o trauma continue recalcado.

A partir daí, ainda em Lacan, questiona-se sobre a insistência do trauma; o fato dele sempre reaparecer, ressurgindo em forma de repetição. Cabe aqui ressaltar que a repetição é a atualização da resistência do sujeito. Sendo a repetição, resistência posta em ato, ela faz com que o sujeito, ao invés de colocar em palavras, atue, distanciando-se de suas lembranças. A resistência continua atuando e o sujeito não é capaz de simbolizar aquilo que está repetindo, remetendo-o ao impossível do real. É esse impossível que faz com que o trauma insista por meio da repetição. Entendendo-se, portanto, a repetição em relação a algo de sempre faltoso, Lacan coloca que sua eficácia se deve à restauração do que está ocultado no inconsciente (LACAN, 1964, p.137).

E de que se trata essa restauração? Segundo o Minidicionário Aurélio, a palavra restauração pode ser entendida como uma recuperação, uma reparação. Além disso, segundo o mesmo autor, ela também é definida como "pôr de novo em vigor". Assim, ao se restaurar uma obra de arte, por exemplo, continuará sendo a mesma obra de arte. Dessa forma, o que se restaura, o que se coloca novamente em vigor, continua sendo a mesma coisa, permanecendo com o mesmo sentido. Voltando à repetição enquanto restauração do que está ocultado no inconsciente, pode-se dizer que isso que está ocultado continua tendo o mesmo sentido. Ou seja, a repetição não altera o conteúdo do material recalcado, nem mesmo ameniza-o. Ela faz com que esse conteúdo seja atualizado por meio da resistência, sem que o paciente o saiba, não sendo, portanto, revelado. "Tudo que, na repetição, varia, modula, é apenas alienação de seu sentido" (LACAN, 1964, p. 62). Isso quer dizer que essa variação não torna o sentido acessível à consciência. É através desse sentido velado que se deve compreender que a repetição demanda o novo. Ou seja, ela atualiza o material recalcado (que é sempre o mesmo) variando as significações, procurando lhe dar novas representações. É nesse sentido que a repetição demanda o novo a partir daquilo que está recalcado.

A repetição pode ser identificada de várias maneiras na vida do sujeito, sobretudo na relação entre paciente e analista. O que estrutura essa relação analítica é a regra fundamental da psicanálise, o método da livre associação. Este é definido como um meio privilegiado de investigação inconsciente, no qual "o paciente deve exprimir todos os seus pensamentos, idéias, imagens e emoções. Tais como se apresentam a ele, sem seleção e restrição, mesmo que tais materiais lhe pareçam incoerentes, impudicos, impertinentes ou desprovidos de interesse." (CHEMAMA, 1995, p.22). Tal método faz com que as resistências do paciente 
sejam suspensas, levando-o a associações que o remetem a seu passado recalcado. No entanto, quando o paciente começa a trazer suas lembranças à tona, ele repete, ele atua esse material recalcado. "O recordar imediatamente abre caminho à atuação (acting out). Daí por diante, as resistências determinam a seqüência do material que deve ser repetido." (FREUD, 1914, P.198).

Portanto, o que cabe ao analista frente a essa resistência do paciente que está sempre presente, tornando o acesso ao recalcado impossível? O que se concebe como meio de fazer com que o paciente baixe a resistência e possa, dessa maneira, tomar conhecimento de sua história, é o manejo da transferência. Esta, ao mesmo tempo em que pode se constituir como uma resistência ao tratamento, pode também ser um meio de dissolver essa resistência. É por isso que seu manejo torna-se importante. "À primeira vista, parece ser uma imensa desvantagem, para a psicanálise como método, que aquilo que alhures constitui o fator mais forte no sentido do sucesso nela se transforme no mais poderoso meio de resistência" (FREUD, 1912, p.135). O que o tratamento analítico busca é tornar acessível à consciência do paciente o material que está recalcado, permitindo que ele aproprie-se desse conhecimento e possa superar sua conduta. Nesse caso, as resistências do paciente se erguem, impossibilitando o acesso ao conteúdo recalcado. Mas para que esse fenômeno fique mais claro, abordar-se-á o conceito de transferência para uma melhor compreensão de como ela opera na praxis psicanalítica.

A transferência, sucintamente, pode ser definida como sendo um "vínculo afetivo intenso, que se instaura de forma automática e atual, entre o paciente e o analista..." (CHEMAMA, 1995, p.217). Esse afeto se deve ao fato de o paciente transferir à figura do analista, a forma de relação que tem ou que teve com outras pessoas no percurso de sua vida. Freud em Fragmento da análise de um caso de histeria, em que analisa o caso Dora, coloca que as transferências:

São reedições, reproduções das moções e fantasias que, durante o avanço da análise, soem despertar-se e tornar-se conscientes, mas com a característica (própria do gênero) de substituir uma pessoa anterior pela pessoa do médico. Dito de outra maneira: toda uma série de experiências psíquicas prévia é revivida, não como algo passado, mas como um vínculo atual com a pessoa do médico. (FREUD, 1905, p.110).

Nessa relação na qual o paciente substitui uma pessoa conhecida pela pessoa do analista, ocorre que o afeto suscitado na relação vivida anteriormente é da mesma forma suscitado na relação analítica. No entanto, a transferência tanto pode se referir a sentimentos afetuosos quanto a sentimentos de hostilidade em relação ao analista, consistindo em transferência positiva e negativa, 
respectivamente. Os sentimentos afetuosos são admissíveis à consciência do paciente e essa transferência positiva tem prolongamentos no inconsciente, que se "acham geneticamente vinculadas à sexualidade e se desenvolveram a partir de desejos puramente sexuais, através da suavização de seu objetivo sexual, por mais puros e não sensuais que possam parecer à nossa autopercepção consciente." (FREUD, 1912, p.140). O que se tem, são impulsos sexuais recalcados que são transferidos à pessoa do analista pelo fato deste estar, para o paciente, substituindo uma relação de amor vivida anteriormente. Ao mesmo tempo em que o paciente tem consciência de seus sentimentos de amizade, confiança, simpatia e outros sentimentos amistosos, ele não se dá conta de seus sentimentos sexuais, visto que estes continuam recalcados. Na transferência negativa, os sentimentos são de agressividade e desconfiança em relação ao analista, mas que não se identificam ao ódio, e sim a um sentimento de ambivalência. Esta comporta simultaneamente sentimentos afetuosos e de agressividade, tornando tal relação confusa na medida em que ambos os sentimentos são atuados em relação à mesma pessoa do analista. A partir de uma passagem da análise do caso Dora realizada por Freud, pode-se ter uma idéia de como se dá não só a transferência negativa, mas a transferência enquanto atuação: “...ela vingou-se de mim como queria vingar-se dele, e me abandonou como se acreditara enganada e abandonada por ele. Assim, atuou uma parte essencial de suas lembranças e fantasias, em vez de reproduzi-las no tratamento" (FREUD, 1905, p.113).

É nessa atuação, em que se deixa de lado o conteúdo reprimido, que se manifestam as resistências do paciente. "Assim, a transferência, no tratamento analítico, invariavelmente nos aparece, desde o início, como a arma mais forte da resistência, e podemos concluir que a intensidade e persistência da transferência constituem efeito e expressão da resistência." (FREUD, 1912, p.139). No entanto, no caso da transferência positiva, desde que não seja permeada de impulsos sexuais recalcados, a resistência não se coloca como um empecilho ao tratamento. Ao contrário, tal transferência faz com que o paciente tenha maior confiança no analista, permitindo-se revelar-lhe mais facilmente aquilo que ele sente dificuldade em falar. Já na transferência negativa e na transferência positiva de impulsos sexuais recalcados, a resistência torna-se um fator oposto ao tratamento. Isso se dá porque o paciente, sem saber o que está ocorrendo, atribui aos afetos que são revividos na transferência, um caráter de atualidade e de realidade. Portanto, ao mesmo tempo em que as resistências constituem um fator contrário ao tratamento, é através de sua suspensão que o analista pode vir a trazer à luz as emoções amorosas secretas e esquecidas dos pacientes. Assim, Freud (1912, p.143) coloca em relação à transferência: "não se discute que controlar os fenômenos da transferência representa para o psicanalista as maiores 
dificuldades; mas não se deve esquecer que são precisamente eles que nos prestam o inestimável serviço de tornar imediatos e manifestos os impulsos eróticos ocultos e esquecidos do paciente."

Ao que parece, essa atuação que se dá na transferência tem o mesmo caráter daquela que ocorre na repetição. De fato, ambas se manifestam enquanto resistência do paciente, atualizando o material recalcado sem que o saiba ao invés de despertar suas lembranças. "A partir das reações repetitivas exibidas na transferência, somos levados ao longo dos caminhos familiares até o despertar das lembranças, que aparecem sem dificuldade, por assim dizer, após a resistência ter sido superada." (FREUD, 1914, p. 201). Mas afinal, no que esses dois conceitos, repetição e transferência, que até aqui foram abordados com certa similaridade, no que eles se diferenciam? Uma das diferenças que se mostra importante entre tais conceitos está em que a transferência se manifesta na relação com alguém, a quem se fala, como coloca Lacan. (1961, p.177). Portanto, o que está em jogo é a reprodução em ato que se manifesta nessa e/ou para essa relação. Apesar de a repetição também ser uma reprodução, esta se constitui da atualização do material recalcado. Já a transferência, também é a atualização da realidade inconsciente, mas que se estabelece nessa relação, sendo transferida à pessoa do analista. A transferência se perpetua dentre as diversas relações que o sujeito tem em seu meio social, mas é somente na análise que tal fenômeno é revelado.

Para que o analista faça uso dessa transferência em benefício do tratamento, deve-se recorrer ao manejo da transferência. Neste, o analista deve identificar as resistências que operam, tornando-as conscientes ao paciente. Sob o domínio da regra fundamental, o que se busca é que o paciente diga ao analista aquilo que lhe vem à mente, no entanto, o que se articula são as resistências do paciente postas em ato. Esta ocorrência torna-se mais provável, principalmente, frente à transferência negativa ou à transferência positiva com impulsos sexuais recalcados, pois nesses casos, o analista deve baixar a resistência do paciente para que ele venha a substituir o repetir pelo recordar. Para que as resistências sejam superadas, o analista deve revelá-las ao paciente, fazendo com que este as reconheça. Além disso, "deve-se dar ao paciente tempo para reconhecer melhor esta resistência com a qual acabou de se familiarizar, para elaborá-la, para superá-la, pela continuação, em desafio a ela, do trabalho analítico segundo a regra fundamental da análise." (FREUD, 1914, p.202). No entanto, somente tendo uma relação transferencial bem estabelecida que o analista torna-se capaz de trabalhar essa resistência. Por meio das associações livres, o analista pode vir a identificar os impulsos pulsionais recalcados que estão alimentando as resistências do paciente. Para que essa relação transferencial se estabeleça, é necessário que o paciente já tenha tornado consciente o fenômeno da 
transferência, superando sua resistência e fornecendo material para o trabalho analítico. É nisto que o manejo da transferência é um importante instrumento, recalcando a compulsão do paciente à repetição e transformando-a em um motivo para recordar (Ibid., p.201).

$\mathrm{O}$ que faz com que o paciente transfira seus afetos à pessoa do analista, é o fato dele supor que o analista seja aquele que tem um saber do que ele busca sobre si mesmo (CHEMAMA, 1995, p.218). Como na transferência tem-se uma reprodução em ato que se manifesta, nesse caso, na presença do analista e que é mediada pela fala, o paciente se dirige àquele em quem ele pressupõe um saber. Lacan articula que é nisso que se funda a transferência, o analista enquanto sujeito suposto saber, aquele em quem o paciente pressupõe o saber sobre si (LACAN, 1971, p.30). Porém, este saber é próprio do sujeito, mesmo sem que ele o saiba. É um não-saber. Frente a isso, o analista deve suspender seu saber para que o saber do paciente advenha. Apesar de o sujeito suposto saber ser a condição para a transferência, "o que a psicanálise revela é um saber não-sabido por si mesmo" (LACAN, 1971, p.17). Afinal, esse saber, "ele é suposto saber aquilo a que nenhum poderia escapar, uma vez que a formule - pura e simplesmente, a significação." (LACAN, 1964, p.239). O fato é que nunca existirá um saber que dê conta dos significantes do sujeito, sempre existirá o real, o impossível de simbolizar. Ao se deparar com esse não-saber, o paciente depara-se com sua falta. A transferência, não the dá o saber que ele esperava obter sobre si mesmo, ao contrário, ela opõe-se à revelação desse saber. Como nada pode ser atingido enquanto falta, enquanto o impossível de assimilar, a transferência se constitui como um fenômeno que instala o real, alienando o sujeito do sentido de seu significante primordial, a saber, sua pulsão recalcada. "O efeito de transferência é esse efeito de tapeação no que ele se repete presentemente aqui e agora." (LACAN, 1964, p.140). Frente a essa tapeação, resta ao sujeito persistir nos significantes que o constituem e determinam, buscando satisfazer sua pulsão, mesmo que parcialmente.

Mas o que fazer com essa persistência dos significantes, com a repetição que se manifesta sem que o sujeito o saiba, buscando atingir sua satisfação? $\mathrm{O}$ que dizer do fenômeno da transferência frente a essa tapeação? O que resta ao sujeito trabalhar na praxis psicanalítica? É justamente nesta que a linguagem opera, em que a fala evoca uma resposta, uma interpretação. Portanto, outro fator que diferencia a repetição da transferência, revelando que esta vai muito além de sentimentos afetuosos, é a linguagem. Na medida em que a transferência se manifesta numa relação mediada pela fala, é a linguagem que está em jogo. Enquanto que na repetição a atualização do paciente não é colocada em palavras, não é simbolizada, na transferência é justamente essa simbolização que opera, na 
medida em que a atualização do paciente se dá pela linguagem. Ao demandar o novo, a repetição varia as significações dadas à atualização do paciente. No entanto, essas significações não são associadas a outras, mantendo o sentido velado, separado de seu referencial. "... a questão do significante remete à da repetição: retorno regular de expressões, de seqüências fonéticas, de simples letras que escandem a vida do sujeito, prontas a mudar de sentido a cada vez que ocorrem, que insistem sem qualquer significação definida." (CHEMAMA, 1995, p.199). A transferência, por sua vez, faz com que essas significações sejam simbolizadas na fala que se estabelece no trabalho analítico, abrindo caminho à interpretação. Esta é uma intervenção do analista que procura fazer surgir um novo sentido além do manifesto, fazendo surgir novas significações. No entanto, as associações do sujeito é que devem ser levadas em conta para que a interpretação seja válida.

A transferência, portanto, assume um caráter que vai além da relação entre paciente e analista. Sua interpretação se dá na medida em que o paciente, portador de seu saber, coloca o analista no lugar daquele que o escuta. Ademais, é por meio da fala do paciente, de seus equívocos, que o saber insabido do paciente se manifesta, revelando-se àquele que é suposto saber.

A interpretação é conseqüência de uma relação, e só a posteriori [grifo do autor] é que podemos pensá-la, dimensioná-la em sua efetividade. Mas se é uma relação, na análise, nem por isso é uma relação de pessoas, de pessoalidades, e sim uma relação daquilo que é dito pelo analisante; o lugar de interpretante é constituído pelas tramas aí enunciadas, e a interpretação, desde que o analista seja colocado transferencialmente neste lugar, o que enunciar como interpretação, como pontuação, só será consistente ao conjunto que se compõe e é tramado entre o enunciado e a enunciação, e assim mesmo, se o analista em questão fizer parte da estrutura mesma deste conjunto, pelo seu lugar de escuta. (SOUZA, 1988, p.82).

A transferência é o que permite ao analista, na sua função de escuta, articular o enunciado que se estabelece na fala do paciente com a enunciação, que está por trás desse enunciado e é dada pelos equívocos de sua fala, revelando o conteúdo latente que faz parte do inconsciente. No entanto, essa articulação não é dada ao paciente. Ao contrário, ela é própria do paciente, mesmo que inconscientemente. A interpretação, pontuação do analista, não articula esse saber, mas possibilita que o paciente associe seus significantes.

$\mathrm{O}$ fato de a transferência ser o fenômeno que possibilita a interpretação se dá porque, à medida que o paciente rejeita a interpretação dada pelo analista, lembranças recalcadas são despertadas. O paciente, opondo-se à rememoração, 
acaba por atuar tais lembranças na transferência, constatando-se a presença desse conteúdo inconsciente. Através da interpretação da transferência, na qual se revela a atuação com a pessoa do analista, é dada veracidade à interpretação, suprimindo a resistência do paciente (SAFOUAN, 1991, p.42). A atuação que se dá na transferência remete à impossibilidade inconsciente de passar para a palavra o dizer que surge, que emerge e que pressiona. Na praxis psicanalítica, cabe ao sujeito tratar disso que lhe é impossível, por meio da linguagem. O que dá fundamento à função da linguagem nessa praxis, são os significantes, que não trazem mensagem alguma, mas que são o fundamento da dimensão do simbólico (LACAN, 1972, p.32). É através deles que o sujeito dá representação àquilo que se constitui enquanto falta, podendo significar o real e buscar satisfação a partir dessa significação.

A interpretação se dá no plano do significante, que não é sabido pelo analista. Para que a interpretação seja dada, é importante que se faça no momento em que o paciente esteja pronto para captá-la, prestes a efetuar tal síntese de seu saber. A partir do momento que o sujeito fala sem saber do que se fala, por meio de significantes, é justamente esse saber que se revela enquanto insabido, dando acesso ao que não foi simbolizado pelo sujeito. “... esse saber impossível é censurado, proibido (...) ele é dito em palavras, entre linhas. Trata-se de denunciar a que sorte de real ele nos permite acesso." (LACAN, 1973, p.162). É a fala do sujeito, seus equívocos e suas associações, que faz referência àquilo que lhe é inassimilável. Por este meio, essa brecha que se produz na linguagem, é que o paciente convoca o analista. "Trata-se de fazer dizer, pelo interlocutor suposto, o que motiva a questão mesma do locutor, quer dizer, de encarnar no outro a resposta que já se tem.” (LACAN, 1973, p.189). O sujeito já comporta esse saber inconsciente, o qual escapa em sua fala.

A interpretação é um saber que faz parte do sujeito, um saber como verdade. Ela se dá a partir do enunciado e da enunciação que se estabelecem na transferência, em que o analista interpreta aquilo que é suposto saber, um saber que já é sabido pelo sujeito. "A interpretação não visa tanto o sentido quanto reduzir os significantes a seu não-senso, para que possamos reencontrar os determinantes de toda conduta do sujeito." (LACAN, 1964, p.201). A linguagem permite ao sujeito produzir novas significações a partir dos equívocos de seu discurso, das associações entre seus significantes. É a partir desses traços que se repetem enquanto equívocos que o sujeito convoca o outro, que é sujeito suposto saber. Assim, o analista é situado como aquele que possibilita as significações inacessíveis ao paciente, que são dadas por meio da linguagem.

\section{Como esses conceitos operam na Praxis Psicanalítica}


O que dizer desses conceitos, que são a satisfação, a pulsão, a repetição e a transferência, articulados na praxis psicanalítica? Deve-se buscar desvendar qual relação se estabelece entre eles, na tentativa de levar o sujeito à superação daquilo que o deixa insatisfeito com ele próprio. Há que se observar que a linguagem é fundamental na operação desses conceitos. É na praxis psicanalítica que o sujeito tem a possibilidade de simbolizar sua falta, aquilo que lhe é inacessível, o impossível que instala o real. A linguagem põe o sujeito em condições de simbolizar o real, pois é através dela que o sujeito associa seus significantes e que aquilo que lhe falta se manifesta através dos equívocos de sua fala. A praxis, portanto, é do sujeito, na medida em que é ele que dá relevância às associações que constituem seu saber, mesmo que insabido. $\mathrm{O}$ analista, que deve ignorar seu saber, ocupa o lugar de escuta, estando atento às diversas conotações dos significantes que são dados pelo sujeito. Afinal, uma mesma palavra assume vários sentidos diferentes.

Certamente, esses conceitos se entrelaçam na praxis, pois já que esta é atribuída ao sujeito, é ele próprio que sustenta todos esses fenômenos. Na busca de sua satisfação, é através da linguagem que o sujeito a simboliza. Ao falar dessa satisfação, ou da sua insatisfação, o sujeito dá significantes à sua falta, na tentativa de tamponá-la. O que consta, é a insistência dessa pulsão que busca a satisfação, desencadeando a repetição dos significantes sem que haja significação. Isso quer dizer que o sujeito repete esses significantes através da atuação, sem que eles estejam conscientemente relacionados a qualquer material recalcado. Portanto, a repetição se manifesta como um fenômeno que mantém as resistências do paciente, levando-o a atuar o conteúdo inconsciente ao invés de colocá-lo em palavras. Só na medida em que o paciente se dá conta dessa repetição é que se tem a possibilidade de trabalhá-la. Para que a repetição seja abordada, deve haver uma transferência estabelecida, que permita a suspensão das resistências do paciente para que este perceba sua atuação.

A transferência, portanto, aparece como um fenômeno fundamental da praxis psicanalítica, pois é ela que irá possibilitar a interpretação, daí sim, fazendo com que o sujeito elabore novas significações a partir de sua fala. É a partir de então que se cria uma rede de significações, fazendo com que o sujeito tenha chance de superar sua insatisfação. O sujeito, após se deparar com sua falta, com o real, busca significá-lo, podendo alcançar um novo meio de lidar com esta ausência que se desvela no desencontro daquilo que ele busca satisfazer. Esse é o momento em que o sujeito se depara com a sua verdade, que constitui o seu saber, que na verdade é um não-saber, pois lhe é inacessível. É com essa verdade que o sujeito irá recompor a sua história, tornando-se sujeito dela e não permanecendo 
assujeitado a esse saber que não existe, mas sim sujeito do não-saber que lhe é próprio.

O que move o sujeito na praxis psicanalítica, fazendo com que ele se coloque frente à satisfação de sua pulsão e também frente a sua repetição, é a transferência, pelo fato desta abrir caminho para aquilo que fará surgir novas possibilidades, dadas pela interpretação. O nó que entrelaça os quatro conceitos abordados em relação à praxis, é a transferência, fenômeno que se estabelece em função da linguagem.

\section{Conclusão}

Como se pôde perceber, os conceitos acima desenvolvidos, a saber, a satisfação, a pulsão, a repetição e a transferência, estão permeados pela linguagem, uma vez que se estabelecem na relação entre paciente e analista, operando, portanto, na praxis psicanalítica. Mas tais conceitos, na experiência clínica, encontram-se obscurecidos, uma vez que não são facilmente identificados. O que se buscou realizar, foi uma forma de desenvolvê-los na medida em que houvesse uma sucessão de idéias, apresentando um conceito na seqüência do outro. Para isso, foi necessário deixar de lado outros conceitos que permeiam estes abordados em detrimento de não estender o assunto proposto. Optou-se pela escolha de uma forma de articular os quatro conceitos, porém, há outras maneiras de articulá-los dentro da praxis psicanalítica.

A partir do caminho seguido, conclui-se que a transferência é condição para que haja análise, sendo, portanto, conceito fundamental para a praxis psicanalítica. $\mathrm{O}$ conceito de repetição não foi tomado enquanto fundamental pelo fato de fazer parte de um dos conceitos com o qual a transferência trabalha. $\mathrm{Ou}$ seja, a repetição opera enquanto trampolim para a transferência, pois é ela que denuncia a atuação do paciente que se manifesta para encobrir o material inconsciente. Dessa forma, ela não possibilita que o sujeito crie novas significações para aquilo que lhe é impossível. Possibilidade essa que é dada pela transferência. Portanto, a satisfação da pulsão é atuada na repetição, mas é através da transferência que se trabalha essa satisfação. Na praxis, é ela que, por meio da linguagem, põe o sujeito em condição de simbolizar sua satisfação. Quanto à felicidade almejada pelos pacientes que se sentem insatisfeitos com eles próprios, ela só é possível se o sujeito se convence de sua falta e procura a melhor maneira de significá-la, sem deixar que ela condene seu sentido à alienação. Tendo a sua verdade, o sujeito é capaz de superar a condição que comporta o não-saber que o constitui. 
Conclui-se que a hipótese formulada inicialmente não condiz com aquilo que a pesquisa formulou. Foi estabelecido que somente o conceito de transferência é fundamental na praxis psicanalítica. Com isso, fica aqui a esperança de uma posterior continuidade desse trabalho, principalmente no que concerne à transferência, haja vista a importância de tal conceito. Além disso, outros temas também deixaram de ser abordados ou foram pouco mencionados devido ao objetivo restrito que se focou nesse trabalho. Por isso, fica a sugestão de ampliar esses conceitos, buscando outros fatores que os determinam na psicanálise.

\section{Referências Bibliográficas}

CHEMAMA, R. Dicionário de psicanálise. Porto Alegre: Artes Médicas Sul, 1995.

FREUD, S. (1912). A dinâmica da transferência. In: ___ . Edição Standard Brasileira das Obras Psicológicas Completas de Sigmund Freud. Rio de Janeiro: Imago, v. XII, 1969.

. (1920). Além do princípio de prazer. In: . Edição Standard Brasileira das Obras Psicológicas Completas de Sigmund Freud. Rio de Janeiro: Imago, v. XVIII, 1969.

. (1909). Cinco lições de psicanálise. In: . Edição Standard Brasileira das Obras Psicológicas Completas de Sigmund Freud. Rio de Janeiro: Imago, v. XI, 1969.

. (1905). Fragmento da análise de um caso de histeria. In: Edição Standard Brasileira das Obras Psicológicas Completas de Sigmund Freud. Rio de Janeiro: Imago, v. VII, 1969.

. (1930). O mal-estar na civilização. In: . Edição Standard Brasileira das Obras Psicológicas Completas de Sigmund Freud. Rio de Janeiro: Imago, v. XXI, 1969.

. (1915). Os instintos e suas vicissitudes. In: . Edição Standard Brasileira das Obras Psicológicas Completas de Sigmund Freud. Rio de Janeiro: Imago, v. XIV, 1969.

. (1914). Recordar, repetir e elaborar (novas recomendações sobre a técnica da psicanálise II). In: __ . Edição Standard Brasileira das Obras Psicológicas Completas de Sigmund Freud. Rio de Janeiro: Imago, v. XII, 1969.

. (1915). Repressão. In: Edição Standard Brasileira das Obras Psicológicas Completas de Sigmund Freud. Rio de Janeiro: Imago, v. XIV, 1969. JAPIASSÚ, H. Dicionário básico de filosofia. 3 ed. Rio de Janeiro: Jorge Zahar, 1996. 
LACAN, J. (1971-1972). O saber do psicanalista: seminário 1971 - 1972. Publicação não comercial. Tradução de Ana Izabel Corrêa, Letícia P. Fonsêca e Nanette Zmery Frej. Recife: Centro de Estudos Freudianos do Recife, 1997.

. (1954-1955) O Seminário, livro 2: o eu na teoria de Freud e na técnica da psicanálise. Tradução de Marie Cristine Laznik Penot com a colaboração de Antonio Luiz Quinet de Andrade. Rio de Janeiro: Jorge Zahar Ed., 1985.

. (1960-1961) O Seminário, livro 8: a transferência. Tradução de Dulce Duque Estrada. Rio de Janeiro: Jorge Zahar Ed., 1992.

- (1964) O Seminário, livro 11: os quatro conceitos fundamentais da psicanálise. 2 ed. Tradução de MD Magno. Rio de Janeiro: Jorge Zahar Ed., 1998.

. (1972-1973) O Seminário, livro 20: mais ainda. 2 ed. Tradução de MD Magno. Rio de Janeiro: Jorge Zahar Ed., 1985.

RESTAURAR. In: Mini Aurélio: o minidicionário da língua portuguesa. Rio de Janeiro: Nova Fronteira, 1977.

SAFOUAN, M. A transferência e o desejo do analista. Tradução de Leda Maria Ficher Bernardino. Campinas: Papirus, 1991.

SOUZA, A. M. de. Transferência e interpretação: ensaio clínico lacaniano. Porto Alegre: Artes Médicas, 1988. 